\title{
Competitiveness Evaluation of Chinese Dairy Industry Based on Accelerated Genetic Algorithm Projection Pursuit Model
}

\author{
Chen Hongli $\mathbb{D}^{1,2,3}$ Wu Yanyan, ${ }^{2,3}$ Liu Xiuli $\mathbb{D}^{1,4}$ and Zhang Wenju $\mathbb{1}^{2}$ \\ ${ }^{1}$ University of Chinese Academy of Sciences, Beijing 100049, China \\ ${ }^{2}$ College of Animal Science and Technology, Shihezi University, Shihezi 832000, China \\ ${ }^{3}$ China Xinjiang Tianshan Junken Animal Husbandry Co., Ltd., Shihezi 832000, China \\ ${ }^{4}$ Academy of Mathematics and Systems Science, Chinese Academy of Sciences, Beijing 100190, China \\ Correspondence should be addressed to Liu Xiuli; xiuli.liu@amss.ac.cn and Zhang Wenju; zhangwj1022@sina.com
}

Received 15 April 2020; Revised 23 June 2020; Accepted 14 July 2020; Published 28 August 2020

Academic Editor: Haoran Zhang

Copyright $\odot 2020$ Chen Hongli et al. This is an open access article distributed under the Creative Commons Attribution License, which permits unrestricted use, distribution, and reproduction in any medium, provided the original work is properly cited.

\begin{abstract}
Scientific evaluation of the competitiveness of China's dairy industry is of great significance to the development of regional dairy industry. In view of the fact that the existing evaluation model cannot solve the dynamic nonlinear optimization problem, this paper established a projection pursuit model based on accelerating genetic algorithm and carried on the comprehensive evaluation and dynamic analysis on the competitiveness of dairy industry in China's 31 provinces and cities (not including Hong Kong, Macao, and Taiwan) from five dimensions, namely, basic factors of production, the industry demand conditions, the enterprise competitiveness and growth force, related and supporting industries, and the natural environmental elements. It was found that firstly, from the perspective of time, the development trend of China's dairy industry basically shows a positive trend. With the improvement of national living standards, the competitiveness of the dairy industry is also constantly improved. Secondly, from the perspective of space, regional differences in the competitiveness of the dairy industry are significant. Inner Mongolia, Heilongjiang, Shandong, and Hebei are at the forefront of the development of the industry, while the development of the dairy industry in the rest of the region has a big gap with those areas. From the perspective of regional layout, the advantageous region of China's dairy industry has been preliminarily formed, and the competitive advantage is mainly concentrated in the northern region. Accordingly, the countermeasures and suggestions to enhance the competitiveness of China's dairy industry were put forward.
\end{abstract}

\section{Introduction}

Milk and dairy products are very important parts of healthy diet in the world, which are closely related to people's life and health. In recent years, the global milk production and consumption have shown a continuous growth trend. In 2018, the global milk production and consumption were 506 million tons and 177 million tons, respectively, $1.47 \%$ and $0.25 \%$ higher than those in 2017 . Although the supply and demand of milk has slowed down statistically, milk is still the most important source for the global milk production. With the improvement of people's living standard, the supply and demand of Chinese dairy products is increasing rapidly. Over the past 20 years, China's dairy industry has developed rapidly. The number of dairy cows in stock has increased from 4.887 million yuan RMB in year 2000 to 7.2 million yuan in 2018, and the total production of dairy products has increased from 829,000 tons in 2000 to 26.871 million tons in 2018. The total industrial output value of China's dairy industry also keeps increasing. In 2018, the total industrial output value of China's dairy industry reached 393.7 billion yuan RMB, about 20 times of the 19.5 billion yuan RMB in 2000 (as is shown in Figure 1).

China's dairy industry gradually presents a certain scale effect and has formed well-known brands such as Mengniu, Yili, and Guangming. However, the development of dairy industry in different regions of China is not balanced. From the distribution of milk sources, as shown in Figure 2, the top 


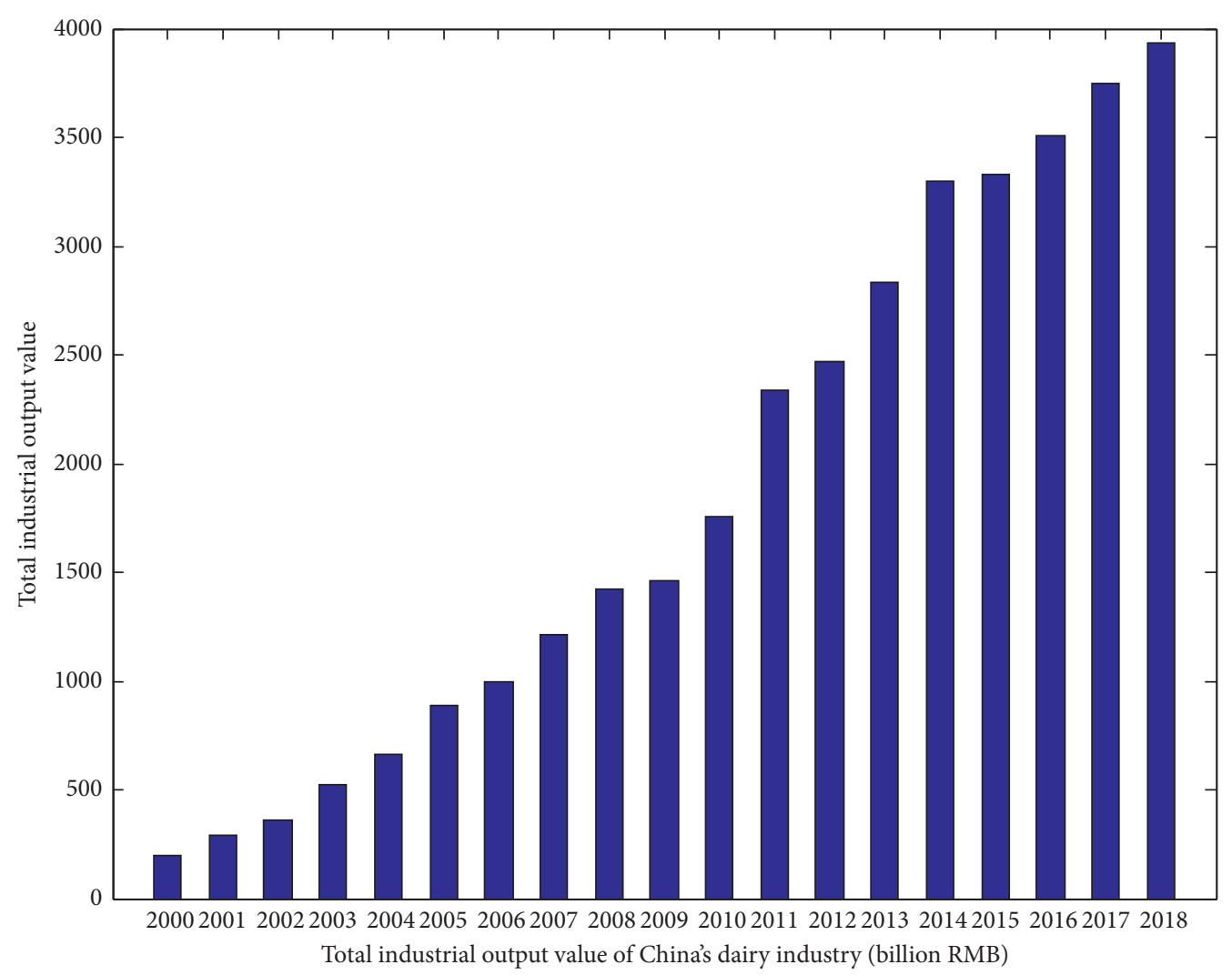

Figure 1: Total industrial output value of China's dairy industry from 2000 to 2018. Data source: China dairy yearbook 2001-2018.

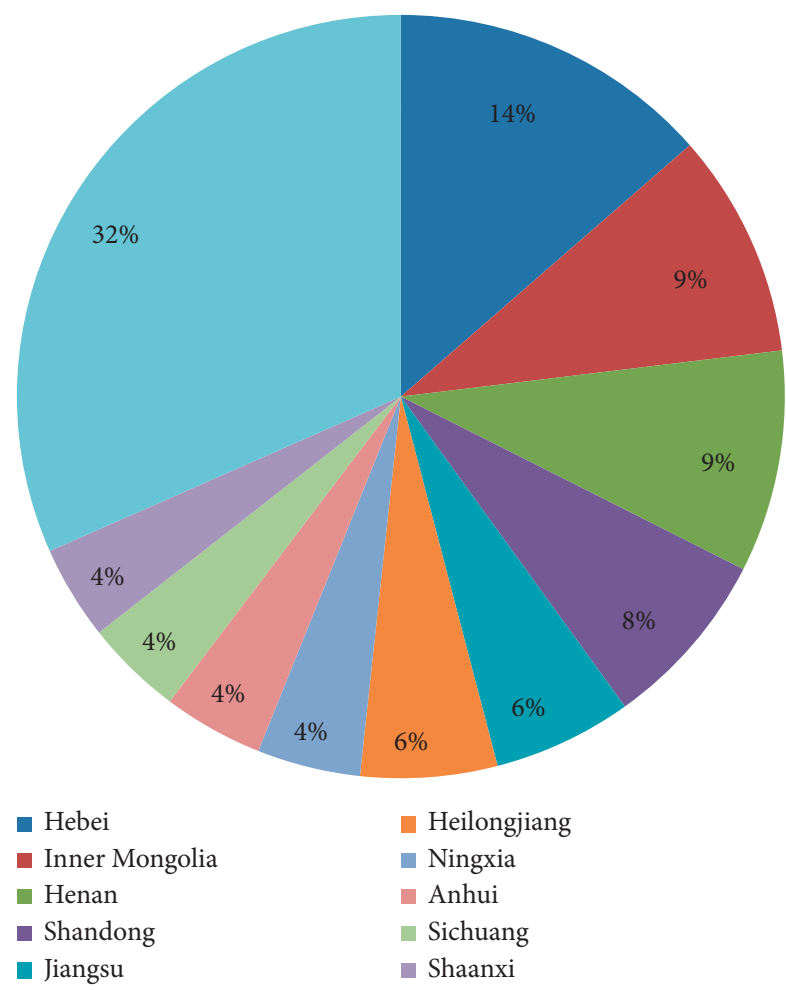

Figure 2: Distribution of milk sources in China in year 2018. Data source: China dairy yearbook 2018.
10 regions in terms of dairy production in year 2018 are Hebei, Inner Mongolia, Henan, Shandong, Jiangsu, Heilongjiang, Ningxia, Anhui, Sichuan, and Shaanxi. Among them, Hebei province ranked first in the output of dairy products in year 2018, accounting for 13.59 percent of the country's total output. Hebei produced 3.6529 million tons of dairy products in year 2018. In year 2018, Inner Mongolia ranked second with a production of 2.54882 million tons of dairy products. In year 2018, Henan ranked third in dairy production with $2.516,200$ tons. The root cause of unbalanced development of dairy industry in different regions is that, in addition to regional support for the industry, it is also closely related to natural environmental factors and basic industrial conditions. In terms of sales revenue, Mengniu, Yili, and Guangming were 68.977 billion RMB, 78.976 billion RMB, and 20.986 billion RMB in year 2018, respectively, accounting for $59.24 \%$ of the national total output. The industry concentration degree is increasingly high (as is shown in Figure 2).

At present, the dairy industry has become an important industry for China to promote regional industrial restructuring and increase farmers' income. Even in some regions (such as Xinjiang and Inner Mongolia), the dairy industry has increasingly become the pillar of local industrial development. Relevant ministries and commissions of the state have also paid close attention to the development of China's dairy industry, providing a favorable environment for the development of China's dairy industry. In year 2018, the 
General Office of the State Council issued Opinions on Promoting the Revitalization of the Dairy Industry to ensure the quality and safety of dairy products and comprehensively accelerate the revitalization of the dairy industry to ensure the quality and safety of dairy products. Opinions on Further Promoting the Revitalization of the Dairy Industry jointly issued by nine ministries and commissions put forward that the national dairy output should reach 45 million tons by 2025 and the quality, efficiency, and competitiveness of China's dairy industry should be effectively improved [1].

Despite the rapid development of China's dairy industry, the corresponding demand for dairy products in China is also very large, so the total amount of dairy imports in China continues to increase. According to the statistics of the General Administration of Customs [2], in 2019, China's dairy imports totaled 2.973 million tons, an increase of $12.8 \%$ year-on-year, and the import value was 11.13 billion US dollars, an increase of $10.6 \%$ year-on-year. With the influence of novel coronavirus pneumonia, China is now consuming 34.3 kilograms of dairy products per capita, and the consumption of dairy products per capita is only $1 / 3$ of the world average, 1/2 of developing countries, and 1/7 of developed countries. The total import volume of dairy products may increase significantly. However, China's dairy trade deficit continues to expand, seriously affecting the rapid development of China's dairy enterprises.

In a word, China's dairy industry has made some achievements, but the international competitiveness of China's dairy industry is far behind that of other countries in the world and does not have comparative advantages. Although there is fierce competition between different countries, the competitiveness of dairy industry among various regions in China is also very worthy of attention. Professor Porter's research on the practice of various countries shows that the fierce domestic market competition plays an important role in the cultivation, formation, and maintenance of the international competitive advantage of the industry. Therefore, it is of great significance for the rapid promotion and sustainable development of the competitiveness of China's dairy industry to build a scientific evaluation index system and to analyze and tap into the overall level and regional differences of the competitiveness of China's dairy industry.

\section{Literature Review of Regional Industrial Competitiveness}

The studies of regional dairy industry competitiveness are mainly based on the industrial competitiveness theory. At present, domestic and foreign researches mainly focus on the following aspects:

(1) The proposal of industrial competitiveness and its formation mechanism: The study of industrial competitiveness can be traced back to the theory of comparative advantage in the period of classical economics and the theory of factor endowments developed by Heckscher-Ohlin and Vernon's dynamic comparative advantage theory. Based on the theory of comparative advantage, the authors in [3] proposed the "diamond model," which has become a relatively perfect analytical framework for the theory of industrial competitiveness. Many experts revised and supplemented the theory of industrial competitiveness based on factor endowment theory, dynamic comparative advantage theory, or "diamond model" [4-10].

(2) Key factors affecting industrial competitiveness: The authors of [4] believed that the industrial competitive advantage mainly depends on the production factor structure of a country and the production factor input structure of the product. The authors of [5] believed that, in addition to national production factor structure, product life cycle was also an important factor affecting industrial competitive advantage. According to [3], there are five factors that affect the industrial competitive situation, which are the threat of new entrants, the bargaining power of buyers (customers), the threat of substitutes (or services), the bargaining power of suppliers, and the competitive situation of existing competitors. The authors in [6] believed that economies of scale, product differentiation, and global competitive strategy are important factors affecting the international competitive advantage of industries. At the same time, domestic scholars mainly study the key factors of its competitiveness from the industrial level. The authors in [11] believed that the advantages of factor endowment, division of labor innovation, and transaction efficiency can improve the comprehensive competitive advantages of China's high-tech manufacturing industry. The authors in [12] proposed that intellectual capital will exert profound and extensive influence on industrial competitiveness. The authors in [13] believed that independent innovation has a great impact on the international competitiveness of China's manufacturing industry. The authors in [14] believed that knowledge production, knowledge capitalization, and manufacturing basis can enhance the industrial competitiveness of a country.

(3) The evaluation methods to study the industrial competitiveness of a specific country or region: For national or regional industrial competitiveness evaluation, experts and scholars at home and abroad built industry competitiveness evaluation index system and used quantitative evaluation model to analyze the industrial competitiveness evaluation. The main evaluation models include analytic hierarchy process (AHP) [15-19], principal component analysis (PCA) [20-22], fuzzy comprehensive evaluation [23-25], grey correlation method [26-29], SEM method [30-32], and location entropy model [33-35]. The competitive power evaluation method evaluates the industrial or regional competitive power from different angles and various fields and finally puts forward targeted countermeasures and suggestions. 
(4) Relevant research on dairy industry competitiveness: In terms of competitiveness of dairy industry, relevant literatures, based on the theory of comparative advantage, compared the competitive advantages of regional dairy industry and its influencing factors, evaluated the sustainable development level of regional dairy industry by constructing relevant indicators, and conducted comprehensive evaluation and dynamic analysis on the development of competitiveness of dairy industry [36-42].

According to the above literature review, domestic and foreign experts and scholars have studied the industrial competitiveness from various perspectives and fields, but there are few studies on the competitiveness of regional dairy industry. Existing literature on the competitiveness of regional dairy products is based on the static analysis of data in a certain region or at a certain time. The relevant evaluation methods are relatively subjective and do not pay attention to the changes in the competitiveness of China's dairy industry in the development process. Aiming at the above problems, this paper adopted projection pursuit model (PP for short) to comprehensively evaluate and dynamically analyze the competitiveness of dairy industry of 31 provinces and regions in China from 2007 to 2016 and studied the panel data of 31 provinces in China for 10 years, which is comprehensive and can reflect the development and change process of regional dairy competitiveness. Projection pursuit model can determine the weighing values of assessment index system by means of dimension reduction method, which outperforms AHP and DEA methods. However, the projection pursuit model has the problems of nonlinear solution problem. Therefore, this paper introduced the accelerating genetic algorithm for real number coding global solution, which can guarantee the stability of the model results.

The basic idea of projection pursuit model is to project the high-dimensional data into the low-dimensional subspace through some combination, find the projection that can reflect the high-dimensional data structure or characteristics by maximizing or minimizing a projection index, and analyze the data structure in the low-dimensional space to achieve the purpose of analyzing and studying the highdimensional data [43, 44]. However, for high-dimensional nonlinear problems, the accuracy model of PP is not high, the optimal projection direction is unstable, the algorithm parameters are uncertain, it is easy to fall into local optimum, and there are premature convergence and other additional problems [45]. Therefore, the accelerated genetic algorithm can simply deal with the global optimization problem in PP model and obtain the best projection with fast convergence speed, high accuracy, and good robustness. As China's dairy industry plays an important role in the national agricultural development strategy, the research in this paper is based on 31 provinces and cities in China, which can quantify the characteristics of each region and guide the development of China's dairy industry. The main objectives of this paper are as follows: (1) to build a scientific and reasonable evaluation index system of China's dairy industry competitiveness and to improve the nonlinear and discrete defects of the PP model by accelerating genetic algorithms; (2) to construct the projection pursuit model with relatively simple algorithm architecture and parameters, which runs an efficient solution algorithm; (3) to achieve comprehensive evaluation and dynamic analysis of the competitiveness of China's dairy industry from both horizontal and vertical aspects and to find out the characteristics of regional spatial distribution and the main impact factor.

\section{Model Construction}

3.1. Construction of Evaluation Index System. There are many factors involved in the competitiveness of dairy industry. Google Academy, China HowNet, and related websites are searched with keywords as "dairy products" and "competitiveness" and some competitiveness evaluation indexes are collected. In combination with the views of experts and scholars such as Porter [45] and Cho and Chang Moon [46] the relevant summary of the competitiveness evaluation index system of dairy industry in this paper is constructed, as shown in Table 1.

According to the research results in recent years and combined with the statistical data characteristics of China's dairy products, five factors are used to evaluate the competitiveness of the dairy industry, namely, production factors, industry demand conditions, enterprise competitiveness and growth force, related and supporting industries, and natural environment factors. This paper, based on the related literature and analysis, selected 20 individual indicators and constructed an evaluation system reflecting the competitiveness of the Chinese dairy industry (as is shown in Table 2).

3.2. Evaluation Model Construction. In view of the fact that AHP, fuzzy comprehensive evaluation, and other models that are greatly influenced by subjective factors are adopted in most relevant evaluation methods, this paper constructed a projection pursuit model (PP), in order to evaluate the competitiveness of dairy industry in 31 provinces and cities in China in a more objective scientific and reasonable way. The values of multidimensional evaluation index were projected into one-dimensional projection data. Real coded accelerating genetic algorithm (RAGA) was introduced into the PP model for the calculation of the optimal projection direction. The impacts on the dairy industry competitiveness were analyzed according to the size of projection value of each index, and the competitiveness level of regional dairy industry was determined according to the projection values [52]. The construction process of PP model is as follows:

Step 1. Nondimensional index data: due to different evaluation index data, each evaluating index is nondimensional in order to reduce the influence of raw data for the final evaluation results. It is assumed that the sample set at the $k$ th year is $\left\{x_{k}(i, j)\right.$, $i=1,2, \ldots, n ; j=1,2, \ldots, m\}$, where $n$ represents the number of evaluated areas, $m$ is the number of evaluation indexes, and $k$ is the year. In this paper, the 
TABLE 1: Summary of competitiveness evaluation indexes of dairy industry.

\begin{tabular}{ll}
\hline Scholar (year) & Evaluation index system
\end{tabular}

Wijnands et al. (2010) Growth in export share on the world market, annual growth in labor productivity of the daily industry, and

[47]

Nica (2017) [48]

Ramphul (2019) [49]

Seyiti and Deng (2013)

[42]

Ma and Yang (2017)

[38]

Han and Cheng (2015)

[41]

$\mathrm{Xu}(2019)[50]$

\section{annual growth in real value added of the food industry}

Net turnover, average number of employees, work productivity, gross profit, and profit rate

Cost of milk production, farm size, infrastructure for milk collection, milk processing capacity, and quality of dairy products

Raw milk share, capital share, location quotient, market share, total labor productivity, asset profit rate, per capita GDP index, and technical market turnover index

The number of cows on hand, the output of raw milk, the area of pasture land, the average number of all employees, the annual per capita consumption of dairy products, the total profit, the annual disposable income, sales revenue, the average price of fresh milk, the total assets, the asset liability ratio, the number of dairy enterprises, the number of breeding bull stations selected for premium seed subsidy, the number of feed processing enterprises, the number of technicians, and the credit environmental science

Share of raw milk, share of capital, proportion of regional output value to total output value, relative specialization coefficient, market share, product sales rate, cost profit rate, asset profit rate, sales profit rate, total labor productivity, average growth rate of total assets, and increase of sales revenue rate

Milk production, per capita share of rattan, total assets of dairy industry, profit, market share of dairy enterprises, value-added tax payable by dairy enterprises, and asset liability ratio of dairy industry

TABLE 2: Competitiveness evaluation index system of Chinese dairy industry.

\begin{tabular}{|c|c|c|c|}
\hline System layer & Objective layer & Index layer & Direction \\
\hline \multirow{20}{*}{$\begin{array}{l}\text { Competitiveness evaluation } \\
\text { index system of Chinese dairy } \\
\text { industry }\end{array}$} & \multirow{5}{*}{ Production factors } & Cow inventory (ten thousands) $X_{1}$ & Positive \\
\hline & & Raw milk yield (ten thousand tons) $X_{2}$ & Positive \\
\hline & & Total area of grassland (ten thousands mu) $X_{3}$ & Positive \\
\hline & & Number of dairy enterprises $X_{4}$ & Positive \\
\hline & & Household consumption of dairy products per & Positive \\
\hline & \multirow[t]{3}{*}{ Industry demand conditions } & Milk per capita $\left(\mathrm{kg} /\right.$ person) $X_{6}$ & Positive \\
\hline & & Annual per capita disposable income (RMB) $X_{7}$ & Positive \\
\hline & & Total profit (100 million RMB) $X_{8}$ & Positive \\
\hline & \multirow{4}{*}{$\begin{array}{l}\text { Enterprise competitiveness and } \\
\text { growth force }\end{array}$} & Industrial sales output value ( 100 million $\mathrm{RMB}) X_{9}$ & Positive \\
\hline & & Market share (\%) $X_{10}$ & Positive \\
\hline & & Number of loss-making enterprises $X_{11}$ & Negative \\
\hline & & Number of bulls (head) $X_{12}$ & Positive \\
\hline & \multirow{4}{*}{ Related and supporting industries } & $\begin{array}{l}\text { Industrial sales output value of feed enterprises (100 } \\
\text { million RMB) } X_{13}\end{array}$ & Positive \\
\hline & & Mixed feed output (ten thousand tons) $X_{14}$ & Positive \\
\hline & & Feed enterprise profit (100 million RMB) $X_{15}$ & Positive \\
\hline & & Annual mean relative humidity (\%) $X_{16}$ & $\begin{array}{l}\text { Fit index } \\
\text { (FI) }\end{array}$ \\
\hline & \multirow[t]{4}{*}{ Natural environment factors } & Annual average temperature $\left({ }^{\circ} \mathrm{C}\right) X_{17}$ & $\begin{array}{l}\text { Fit index } \\
\text { (FI) }\end{array}$ \\
\hline & & Annual extreme maximum temperature $\left({ }^{\circ} \mathrm{C}\right) X_{18}$ & Negative \\
\hline & & $\begin{array}{c}\text { Annual extreme minimum temperature }\left({ }^{\circ} \mathrm{C}\right) X_{19} \\
\text { Annual sunshine hours (hours) } X_{20}\end{array}$ & $\begin{array}{l}\text { Positive } \\
\text { Positive }\end{array}$ \\
\hline & & Annual sunshine hours (hours) $X_{20}$ & \\
\hline
\end{tabular}

number of loss-making enterprises and annual extreme maximum temperatures is negative index; the other indexes are positive indicators. Therefore, positive index, negative index, and fit index are nondimensional.

Nondimensional positive indicators of evaluation index data in the $k$ th year: there is

$$
x_{k}^{\prime}(i, j)=\frac{x_{k}(i, j)-x_{k \min }(j)}{x_{k \max }(j)-x_{k \min }(j)} .
$$

Nondimensional negative indicators of evaluation index data in the $k$ th year: there is

$$
x_{k}^{\prime}(i, j)=\frac{x_{k \max }(j)-x_{k}(i, j)}{x_{k \max }(j)-x_{k \min }(j)} .
$$

Nondimensional fit indicators of evaluation index data in the $k$ th year: there is

$$
x_{k}^{\prime}(i, j)=\frac{1}{\mid x_{k}(i, j)-\text { fitind } x \mid},
$$

where $x_{k}^{\prime}(i, j)$ are the nondimensional results of the evaluation index data in the $k$ the year in (1)-(3) and $x_{k \max }(j)$ and $x_{k \min }(j)$ represent the maximum and minimum values of the evaluation index $j$. 
Step 2. Construction of projection index function: the projection pursuit model forms the optimal projection direction $a=\{a(1), a(2), \ldots, a(m)\}$ by projecting the $m$ th dimensional data $\left\{x_{k}(i, j), j=1,2, \ldots, m\right\}$ into the low-dimensional subspace. Then, the projection value of the evaluation index sample $i$ on the optimal projection direction is as follows:

$$
z(i)=\sum_{j=1}^{m} a_{k}(j) x_{k}(i, j), \quad i=1,2, \ldots, n .
$$

According to this, one-dimensional scatter diagram of projected values is drawn, which requires the projected values to disperse as a whole and gather locally. Therefore, the projection index function related to standard deviation and in-class coefficients is constructed as follows:

$$
Q(a)=S_{z} D_{z}
$$

wherein $S_{z}$ is the standard deviation of the projected value of the evaluation index $z(i)$ and $D_{z}$ is the in-class coefficient of the projected value of the evaluation index $z(i)$. There are

$$
\begin{aligned}
S_{z} & =\sqrt{\frac{\sum_{i=1}^{n}(z(i)-E(z))^{2}}{n-1}}, \\
D_{z} & =\sum_{i=1}^{n} \sum_{j=1}^{m}(R-r(i, j) \times u(R-r(i, j))),
\end{aligned}
$$

where $E(z)$ is the mean value of the sequence of projected values on the optimal projection direction of the evaluation index, $r(i, j)=|z(i)-z(j)|$ is the difference of the projected values on the optimal projection direction, $R$ is the window radius of local density (usually determined according to the experiment), and $u(R-r(i, j))$ is the unit step function. When $R \gg r(i, j)$, there is $u(R-r(i, j))=1$; otherwise it is 0 .

Step 3. Optimized indicator functions: the optimal projection direction is the vector corresponding to the maximum projection index function. For the determined index set $a=\{a(1), a(2), \ldots, a(m)\}$, the change of the optimal projection direction of the evaluation index will make the projection index function $Q(a)$ change. Therefore, the estimation of the optimal projection direction is actually to solve the problem of maximizing the projection index function. The target function is built as follows:

$$
\begin{cases}\max & Q(a)=S_{Z} D_{z} \\ \text { s.t. } & \sum_{j=1}^{m} a^{2}(j)=1, \quad a(j) \in[0,1] .\end{cases}
$$

Step 4. The optimal projection direction of the evaluation index $a^{*}=\left\{a^{*}(1), a^{*}(2), \ldots, a^{*}(m)\right\}$ can be obtained by solution. The optimal projection direction can be understood as the weight. First, it needs to be normalized, and then the normalized value of the optimal projection direction after normalization is substituted into (7) to obtain the optimal projection value of each index $z^{*}(i)$, as follows:

$$
z^{*}(i)=\frac{a^{*}(j) x(i, j)}{\sum_{j=1}^{m} a^{*}(j)}, \quad i=1,2, \ldots, n .
$$

Similarly, the optimal projection value of the spatial angle can be obtained according to the above calculation.

\section{Results and Discussion}

4.1. Vertical Evaluation of Competitiveness of Chinese Dairy Enterprises. In terms of time dimension, this paper selected data from 2007 to 2016 to vertically evaluate the competitiveness of China's dairy industry through the above index system. The data were obtained from China Dairy Yearbook and China Statistical Yearbook from 2008 to 2018. Based on time dimension of 10 years and 20 index numbers, the optimal projection direction is gotten from accelerating genetic algorithm. Set the selected parent generation of initial population size $s=400$, crossover probability $P_{c}=0.8$, mutation probability $P=0.2$, the outstanding individual number is 20 , and the number of acceleration times is 7 , the maximum number of iterations is 200 , and the optimal projection directions are gotten based on the time dimension of each evaluation index, as is shown in Table 3.

In terms of the vertical evaluation of the competitiveness of Chinese dairy enterprises, according to the characteristics of the accelerating genetic algorithm proposed in this paper, the accelerating genetic algorithm (AGA) and the standard genetic algorithm (GA) are solved and simulated on the MATLAB platform, and then the two algorithms are solved iteratively, with the negative value of the objective function as the fitness function and the fitness obtained by projecting the pursuit curve, as shown in Figure 3. It shows that, with the increase of the number of iterations, the convergence speed of AGA is significantly faster than that of GA and the AGA algorithm close to the horizontal coordinate does not change with the increase of the number of iterations, reflecting its convergence stability and convergence reliability. In a word, the performance of AGA is obviously better than that of GA.

The optimal projection direction of each evaluated index in the time dimension is shown in Table 3: the optimal projection direction of eight evaluation indexes is above 0.25 , namely, the industrial sales value, number of lossmaking businesses, feed corporate profits, the sunshine hours throughout the year, mixed feed production, households per capita consumption of dairy products, raw milk production, and the annual per capita disposable income, while there are certain differences but it can be concluded that the factors of production factors, the industry demand conditions, the enterprise competitiveness and growth force, related and supporting industries, and the natural environmental elements have relatively consistent importance in the Chinese dairy industry competitiveness evaluation. Among them, enterprise competitiveness and growth force 
TABLE 3: Optimal projection direction of evaluation index based on time dimension.

\begin{tabular}{lcccccccccccccccccccccccc}
\hline Sequence & 1 & 2 & 3 & 4 & 5 & 6 & 7 & 8 & 9 & 10 & 11 & 12 & 13 & 14 & 15 & 16 & 17 & 18 & 19 & 20 \\
\hline $\begin{array}{l}\text { Index } \\
\begin{array}{l}\text { Optimal } \\
\text { projection } \\
\text { direction }\end{array}\end{array}$ & $X_{9}$ & $X_{11}$ & $X_{15}$ & $X_{20}$ & $X_{14}$ & $X_{5}$ & $X_{2}$ & $X_{7}$ & $X_{12}$ & $X_{10}$ & $X_{13}$ & $X_{18}$ & $X_{6}$ & $X_{8}$ & $X_{1}$ & $X_{16}$ & $X_{3}$ & $X_{4}$ & $X_{19}$ & $X_{17}$ \\
\hline
\end{tabular}

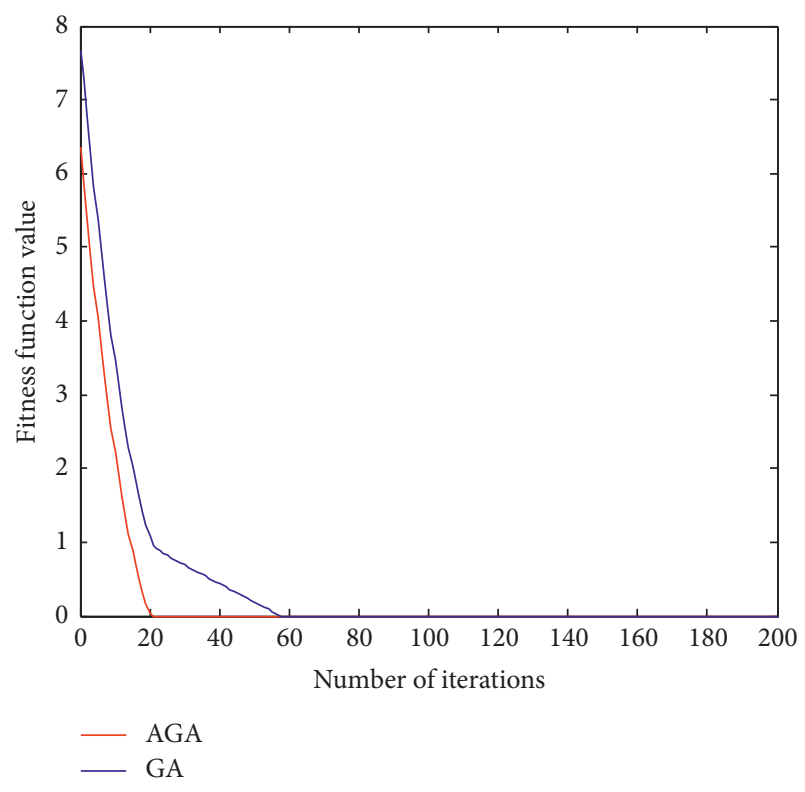

FIgURE 3: Comparison of the fitness curve of projection vector.

are the main factors affecting the competitiveness of China's dairy industry. According to formula (8), the projected value of Chinese dairy industry index based on time dimension is obtained, as shown in Table 4.

According to Table 4, the time dimension weighted value of competitiveness of Chinese dairy industry can be calculated, as shown in Table 5.

According to the results in Table 5, the comprehensive evaluation results of competitiveness of Chinese dairy industry based on time dimension are ranked as follows: $2016>2015>2014>2013>2012>2011>2010>$

$2009>2008>2007$. It can be seen that the development trend of China's dairy industry basically shows a positive trend. With the improvement of the national living standard, the competitiveness of the dairy industry is also constantly improved, from 0.1216 in 2007 to 0.8267 in 2016.

As for the factors of production factor base dimension, it can be seen that although the number of the Chinese dairy industries decreases in recent years, the prairie area does not have too much change, and the cow restock remains the same which reached its peak in 2010 and 2011. With China's dairy industry promoting technological progress and its competitiveness, the final output of raw milk increased from 576,600 tons in 2007 to 965,500 tons in 2016 . Therefore, from 2007 to 2016, the production factor base of China's dairy industry was continuously strengthened, and its competitiveness evaluation value increased from 0.0190 to 0.1040 .

In regard to the dimension of industry demand conditions, with the improvement of China's national living standard, residents' annual per capita disposable income rose gradually, more and more consumer dairy products were considered as a daily life necessity, and household per capita consumption of dairy products increased gradually, and, at the same time as the production of dairy products increased year by year, dairy per capita is also increasing. Therefore, from 2007 to 2016, the demand conditions level of China's dairy industry rose steadily, and its competitiveness evaluation value increased from 0.0129 to 0.1731 .

From the perspective of enterprise competitiveness and growth force dimension, due to the national rectification of dairy enterprises, some unqualified enterprises gradually withdrew from the market, and the total profit and industrial sales value of enterprises increased significantly. The number of bulls as the evaluation index of competitiveness of basic enterprises also showed a trend of increasing year by year with the development of technology. From 2007 to 2016, the overall competitiveness and growth power of enterprises have been rising, and the evaluation value of their competitiveness has increased from 0.0381 to 0.3152 .

From the dimension of related and supporting industries, feed industries, as related and supporting industries of China's dairy industries, have seen a growth at the aspects of mixed feed production and corporate profits expected in year 2015 when the industrial sales value of feed industries suffered a brief decline, which laid a solid industrial foundation for increasing the competitiveness of China's dairy industry. From year 2007 to year 2016, the foundation of relevant and supporting industries was gradually consolidated, and the evaluation value of its competitiveness increased from 0 to 0.1427 .

From the perspective of natural environmental elements dimensions, dairy production, to a great extent, is affected by the natural environmental elements, and regional differences in natural environment factor endowments directly affect the production of dairy products enterprise decision-making and dairy production quality. From the point of historical data, the annual average relative humidity, annual average temperature, annual extreme minimum temperature and extreme maximum temperature, and annual sunshine hours throughout the year can present different degree of volatility, but these factors do not affect the competitiveness of China's dairy industry from overall increase year by year. From 2007 to 2016, the evaluation value of the competitiveness of natural environmental factors increased from 0.0516 to 0.0916 .

4.2. Spatial Competitiveness Evaluation of China's Dairy Enterprises. From the spatial dimension, the data from 31 provinces and cities in China (excluding Hong Kong, Macao, and Taiwan regions) in 2007 to 2016 are regarded as 


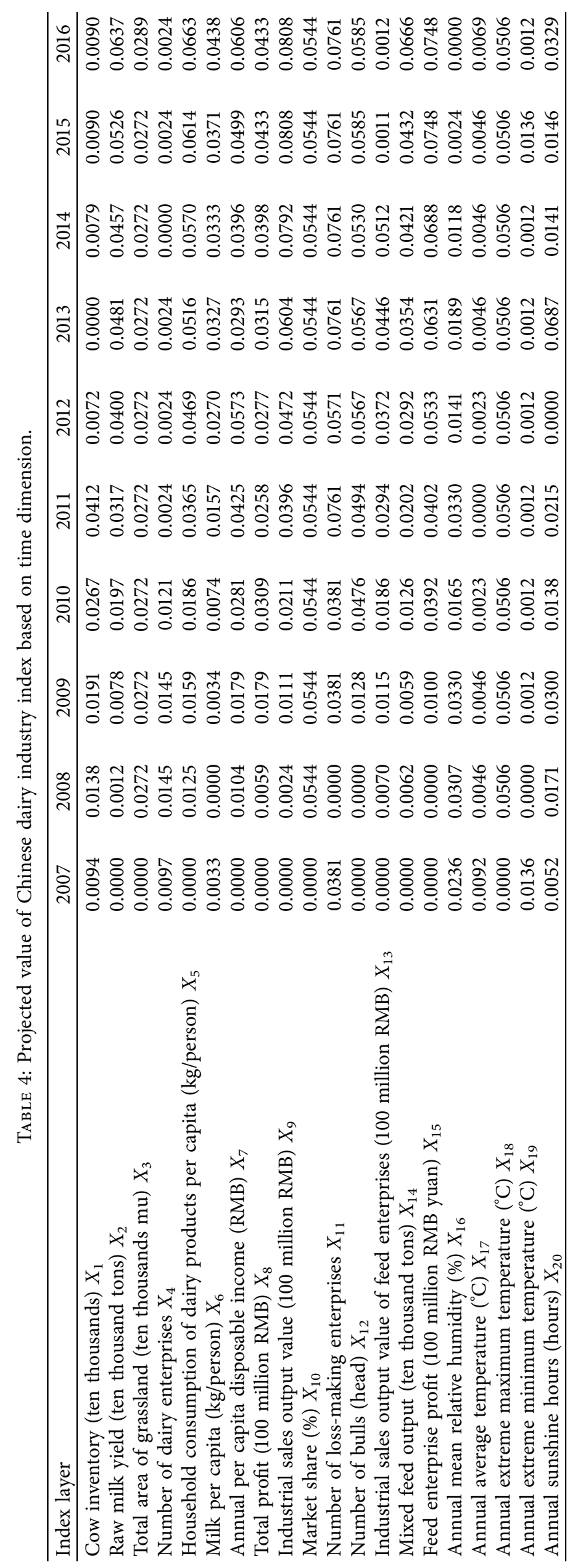


TABLE 5: Evaluation value of competitiveness of Chinese dairy industry based on time dimension.

\begin{tabular}{|c|c|c|c|c|c|c|c|c|c|c|}
\hline Index layer & 2007 & 2008 & 2009 & 2010 & 2011 & 2012 & 2013 & 2014 & 2015 & 2016 \\
\hline Factor base & 0.0190 & 0.0567 & 0.0685 & 0.0856 & 0.1025 & 0.0768 & 0.0777 & 0.0807 & 0.0912 & 0.1040 \\
\hline Industrial demand condition & 0.012 & 0.03 & 0.0517 & 0.0662 & 0.0972 & 0.1337 & 0.1160 & 0.1299 & 0.1508 & 0.1731 \\
\hline Enterprise competitiveness and growth power & 0.0381 & 0.0731 & 0.1395 & 0.1726 & 0.2385 & 0.24 & 0.2518 & 0.2891 & 0.3046 & 0.3152 \\
\hline $\mathrm{d}$ supporting industries & 0.0000 & 0.0132 & 0.0274 & 0.0704 & 0.0898 & 0.1196 & 0.1431 & 0.1621 & 0.1191 & 0.1427 \\
\hline Natural environment factor & 0.0516 & 0.1030 & $0.11 \mathrm{a} 94$ & 0.0845 & 0.1063 & 0.0683 & 0.1440 & 0.0823 & 0.0858 & 0.0916 \\
\hline Comprehensive level & 0.1216 & 0.2833 & 0.4066 & 0.4794 & 0.6343 & 0.6422 & 0.7326 & 0.7442 & 0.7514 & 0.8267 \\
\hline
\end{tabular}

the foundation; a comparative study was conducted to find out the competitiveness level difference between the dairy industries in different regions. The accelerating genetic algorithm was solved with the 31 sample numbers and 20 indexes. Set the selected parent generation of initial population size $s=400$, crossover probability $P_{c}=0.8$, mutation probability $P=0.2$, the outstanding individual number is 20 , the maximum number of iterations is 200 , the times of acceleration are 7 , and the optimal projection direction of each evaluation index on the spatial dimension is gotten as shown in Table 6.

For the horizontal evaluation of competitiveness of Chinese dairy enterprises, according to the characteristics of the accelerated genetic algorithm proposed in this paper, the accelerated genetic algorithm (AGA) and the standard genetic algorithm $(\mathrm{GA})$ are solved and simulated on the MATLAB platform, and then the two algorithms are solved iteratively, with the negative value of the objective function as the fitness function, and the fitness obtained by projecting the pursuit curve is shown in Figure 4. It shows that, with the increase of the number of iterations, the convergence speed of AGA is significantly faster than that of GA, and the AGA algorithm close to the horizontal coordinate does not change with the increase of the number of iterations, reflecting its convergence stability and convergence reliability. In a word, the performance of AGA is obviously better than that of GA.

It can be seen from Table 6 that the number of lossmaking businesses, raw milk production, market share, cow inventory, and sunshine hours throughout the year rank top 5 , which means that production factors base, enterprise competitiveness and growth, and natural environmental elements are the main factors influencing China's dairy industry competitiveness in 31 provinces. According to the optimal projection direction, the projected value of dairy competitiveness of each region was obtained, as shown in Table 7.

In order to clearly analyze the spatial differences in the competitiveness of the dairy industry and explore the status and level of the regional dairy industry in different dimensions, this paper classified and sorted out the regions according to the evaluation index value of the spatial dimension of the competitiveness of the dairy industry. The specific division method is as follows: firstly, the evaluation index values of the spatial dimension of dairy industry competitiveness are arranged in ascending order. The maximum value $z(i)_{\max }=0.681796$ is the optimal competitiveness, and the minimum value $z(i)_{\min }=0.044230$ is the weakest competitiveness; secondly, according to the regional characteristics of China's administrative regions, it is divided into four categories, the evaluation index values are correspondingly converted into four grey categories, and then the comprehensive decision-making measures are calculated by calculating the clustering coefficient of each region; finally, the categories of all regions are determined according to the comprehensive decision-making measures, and the corresponding calculation steps are referred to as $[51,52]$. The result is shown in Figure 5.

As can be seen from Figure 5, there are significant differences in the competitiveness of China's dairy industry in 31 provinces and cities, and there is no overall regional correlation. The most competitive provinces and cities in China's dairy industry include Inner Mongolia, Heilongjiang, Shandong, and Hebei, among which Inner Mongolia dairy industry competition is the leading one. The best projection value of its comprehensive competitiveness is 0.6818 , which is quite obvious compared with the second place 0.5803 in Shandong province. Particularly with the improvement of the concentration degree of Inner Mongolia dairy industry in recent years, its production factor base, industrial demand conditions, enterprise competitiveness and growth, related and supporting industries, and natural environment factors are in a dominant position.

According to the evaluation index value of spatial dimension of competitiveness of dairy industry in Table 7, 31 regions are divided into 4 grades, as is seen in Tables 8-10. As shown in Table 8, the areas ranking high in overall competitiveness have advantages (ranking top 4) in the aspects of production factors base and enterprise competitiveness and growth performance. However, related and supporting industries and the natural environmental elements in these areas have relatively obvious gap, especially the natural environmental elements, only Inner Mongolia ranking above the national average level. Famous dairy enterprises such as Mengniu group, Yili group, Feihe dairy, and Sanyuan dairy are mainly located in such provinces as Inner Mongolia, Heilongjiang, and Hebei. Strong enterprise strength and sufficient milk sources and pastures make these regions highly competitive. Therefore, the provinces with higher overall ranking need to maintain factors of production base and strong force of enterprise competitiveness and growth. Heilongjiang and Hebei at the same time also need to continue exploring industry demand conditions, Inner Mongolia and Heilongjiang should pay more attention to the related and supporting industries, and Shandong, Heilongjiang, and Hebei need to improve the dairy industry needs, natural environmental elements, and sustainable regional dairy competitiveness level. 
TABLE 6: Optimal projection direction of evaluation index based on spatial dimension.

\begin{tabular}{lccccccccccccccccccccc}
\hline Sequence & 1 & 2 & 3 & 4 & 5 & 6 & 7 & 8 & 9 & 10 & 11 & 12 & 13 & 14 & 15 & 16 & 17 & 18 & 19 & 20 \\
\hline $\begin{array}{l}\text { Index } \\
\begin{array}{l}\text { Optimal } \\
\text { projection } \\
\text { direction }\end{array}\end{array}$ & $X_{11}$ & $X_{2}$ & $X_{10}$ & $X_{1}$ & $X_{20}$ & $X_{9}$ & $X_{12}$ & $X_{4}$ & $X_{8}$ & $X_{15}$ & $X_{17}$ & $X_{7}$ & $X_{5}$ & $X_{14}$ & $X_{6}$ & $X_{3}$ & $X_{19}$ & $X_{13}$ & $X_{18}$ & $X_{16}$ \\
\hline
\end{tabular}

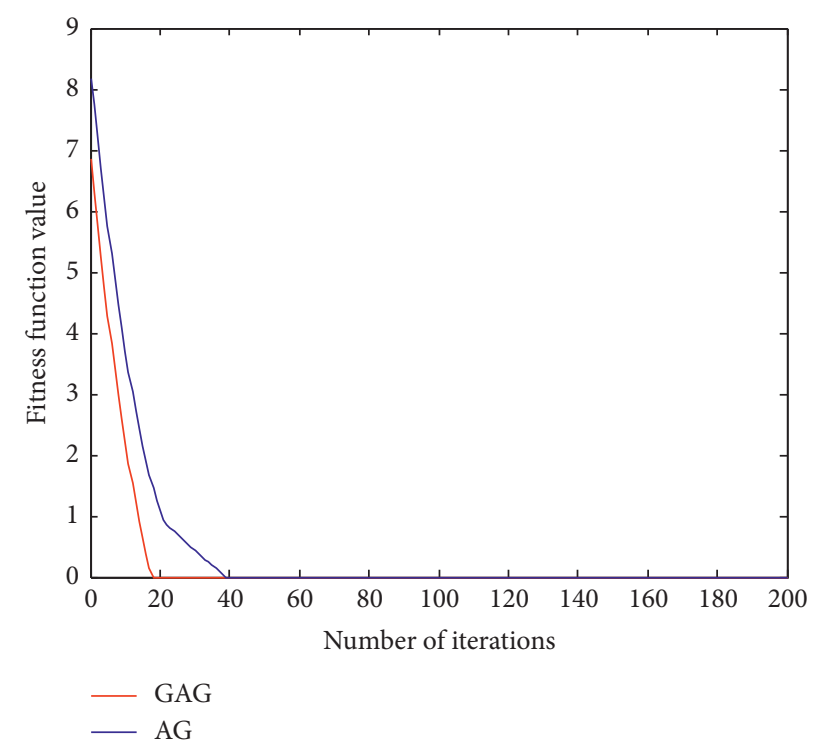

Figure 4: Comparison of the fitness curve of projection vector.

According to Table 9, it can be seen that the corporate competitiveness and growth power in all the regions ranked at the second level, but other factors influencing indicators of competitiveness levels show the instability characteristics, especially the natural environmental elements. Except that Xinjiang and Liaoning are still in the second level, the rest are in a low level. Therefore, in the process of late industry development, the natural environment should be focused to make up for the shortage. Of course, Shanghai, Jiangsu, and Beijing are the provinces with higher level of industrial demand. Due to the relatively developed economy in these areas, people's living standards are relatively high, and the per capita occupancy and demand for dairy products are relatively large. The per capita consumption of dairy products in these three regions accounts for $15.62 \%$ of the national average, and the per capita disposable income accounts for $16.4 \%$ of the national average. The relatively large scale of demand and relatively high per capita disposable income can promote the rapid development of the dairy industry. Therefore, regions at the second level should continue to maintain their competitive advantages of enterprise competitiveness and growth power, and, at the same time, they need to learn from the regions at the first level and strive to get closer to the first level by improving the industry's own ability.

As shown in Table 10, only Chongqing, Hainan, and Guizhou are at the fourth level with evaluation index value of $0-0.1$, so the third level and the fourth level are analyzed together. For the areas whose dairy industry competitiveness ranked relatively lower, their influence factor index competitiveness is also relatively backward. Of course, there are also some areas that have certain advantages, such as Ningxia and Fujian, which have certain industrial competitive advantage on the natural environment factors and industrial demand. That is to say, if the two regions continue to improve the factors of production factor base and enterprise competitiveness and growth, the whole competitiveness level will be updated. The improvement of the competitiveness of dairy industry in other regions requires long-term accumulation of production factors, mining of industrial demand, expansion of enterprise competitiveness and growth power, development of relevant and supportive industries, and optimization of natural environment factors to stimulate the improvement of regional dairy industry competitiveness.

4.3. Comparative Analysis of Evaluation Results. The projection values of time and space dimensions of competitiveness of China's dairy industry obtained from GAG-PP are compared with the calculation results of AHP (subjective evaluation) and entropy weight evaluation (objective evaluation), as is shown in Tables 11 and 12. This paper uses Yaahp software to determine the weight in AHP by [42] and expert consultation. Entropy weight evaluation is used to judge the dispersion degree of an index by entropy value. The smaller the information entropy value is, the greater the dispersion degree of the index is, and the greater the influence (weight) of the index on the comprehensive evaluation is [54]. 


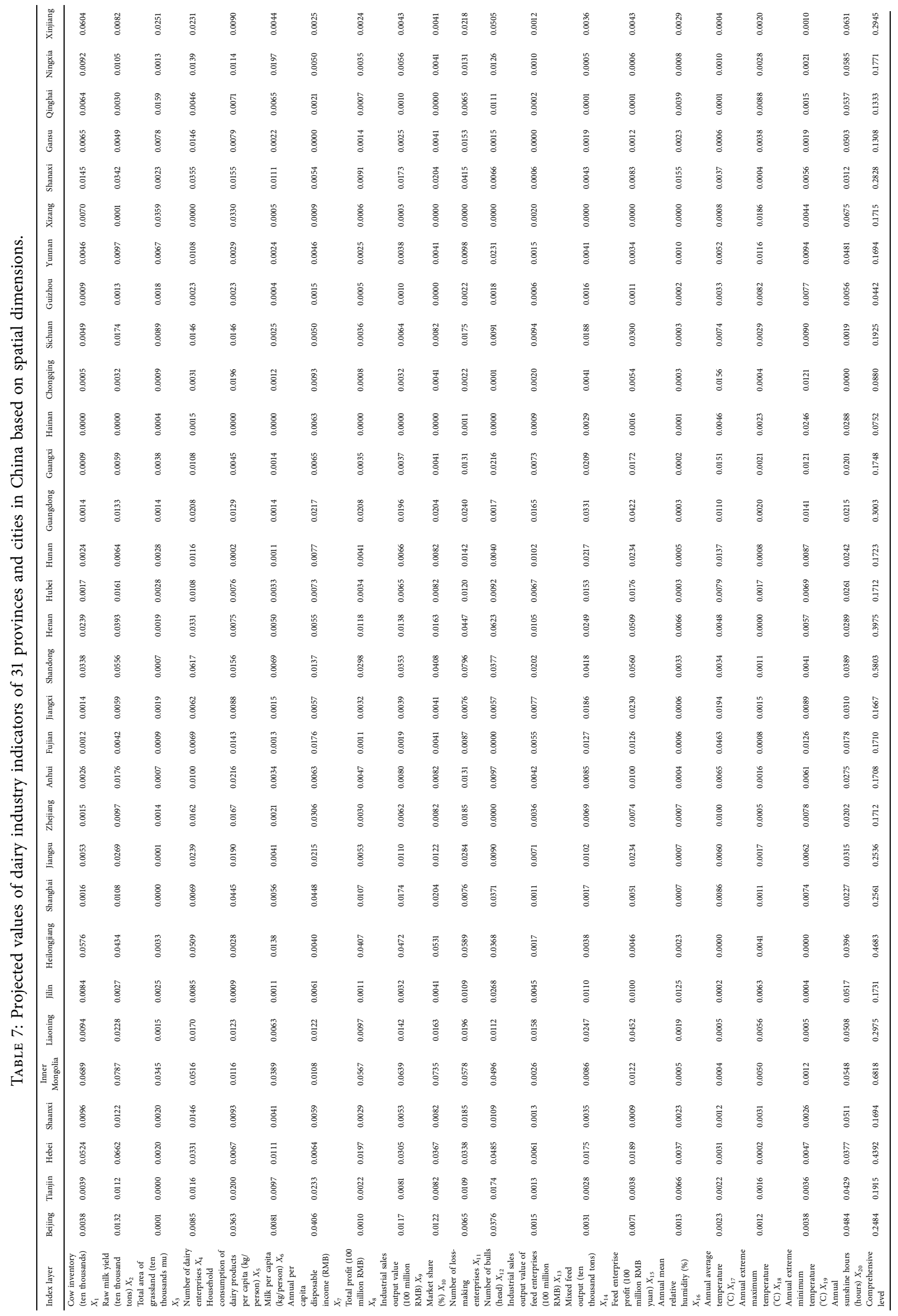




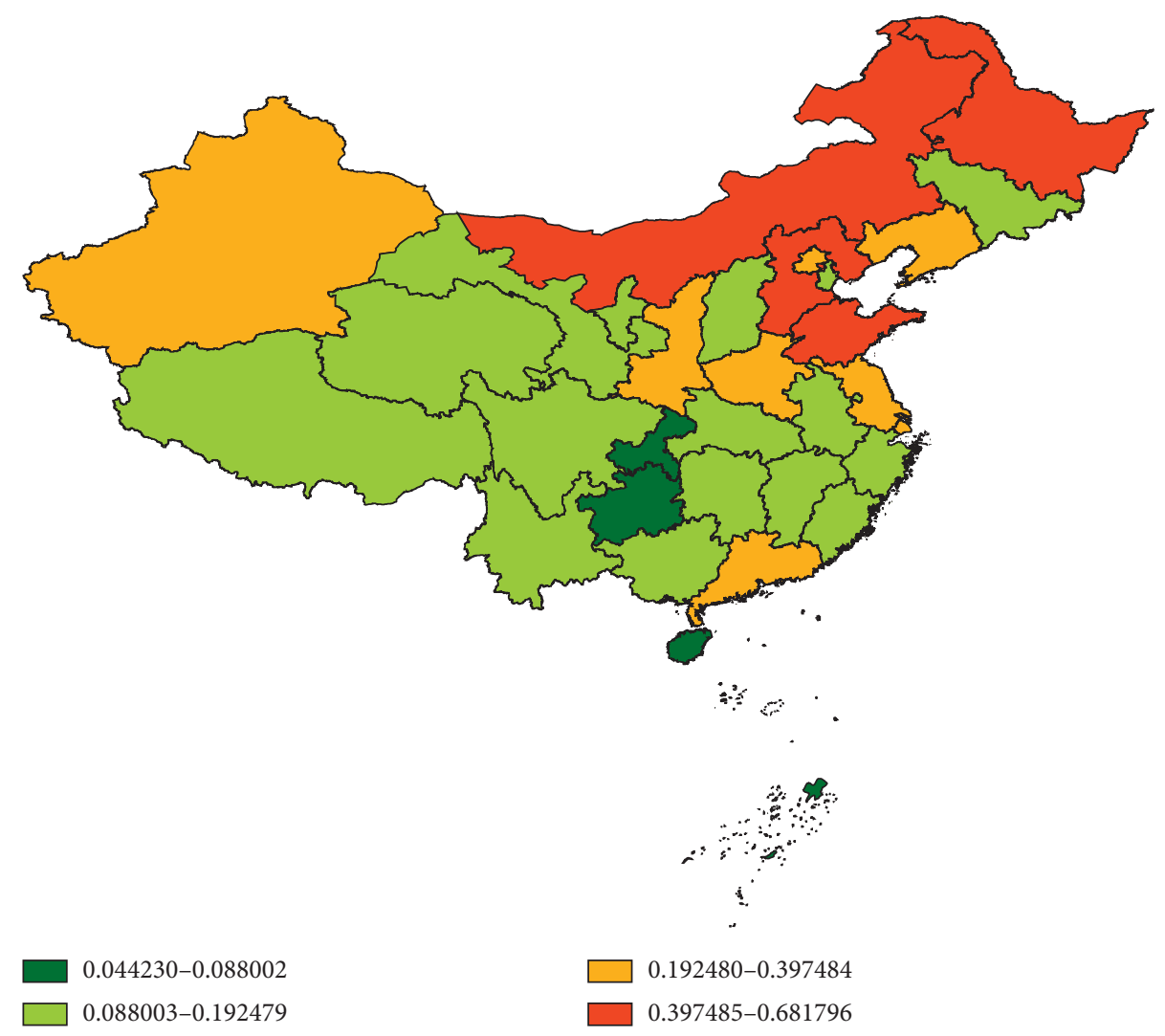

FIGURE 5: Spatial differentiation of competitiveness of Chinese dairy industry.

TABLE 8: Regions with first-level competitiveness.

\begin{tabular}{|c|c|c|c|c|c|c|}
\hline Areas & $\begin{array}{c}\text { Evaluation index } \\
\text { value ranking } \\
{[>0.4]}\end{array}$ & $\begin{array}{l}\text { Factor } \\
\text { base } \\
\text { ranking }\end{array}$ & $\begin{array}{l}\text { Industrial } \\
\text { demand } \\
\text { condition } \\
\text { ranking }\end{array}$ & $\begin{array}{l}\text { Enterprise competitiveness } \\
\text { and growth power ranking }\end{array}$ & $\begin{array}{c}\text { Relevant and } \\
\text { supporting } \\
\text { industries }\end{array}$ & $\begin{array}{l}\text { Natural } \\
\text { environment factor } \\
\text { ranking }\end{array}$ \\
\hline $\begin{array}{l}\text { Inner } \\
\text { Mongolia }\end{array}$ & 1 & 1 & 3 & 1 & 14 & 8 \\
\hline Shandong & 2 & 4 & 7 & 3 & 1 & 17 \\
\hline Heilongjiang & 3 & 2 & 18 & 2 & 20 & 24 \\
\hline Hebei & 4 & 3 & 16 & 4 & 9 & 19 \\
\hline
\end{tabular}

TABLE 9: Regions with second-level competitiveness.

\begin{tabular}{|c|c|c|c|c|c|c|}
\hline Areas & $\begin{array}{c}\text { Evaluation index } \\
\text { value ranking } \\
{[>0.4]}\end{array}$ & $\begin{array}{l}\text { Factor base } \\
\text { ranking }\end{array}$ & $\begin{array}{c}\text { Industrial } \\
\text { demand } \\
\text { condition ranking }\end{array}$ & $\begin{array}{l}\text { Enterprise competitiveness } \\
\text { and growth power ranking }\end{array}$ & $\begin{array}{l}\text { Relevant and } \\
\text { supporting } \\
\text { industries }\end{array}$ & $\begin{array}{c}\text { Natural } \\
\text { environment factor } \\
\text { ranking }\end{array}$ \\
\hline Henan & 5 & 6 & 21 & 5 & 3 & 23 \\
\hline Guangdong & 6 & 13 & 9 & 8 & 2 & 20 \\
\hline Liaoning & 7 & 10 & 14 & 10 & 4 & 12 \\
\hline Xinjiang & 8 & 5 & 23 & 9 & 21 & 5 \\
\hline Shaanxi & 9 & 7 & 12 & 6 & 17 & 16 \\
\hline Shanghai & 10 & 26 & 1 & 7 & 24 & 27 \\
\hline Jiangsu & 11 & 8 & 6 & 12 & 11 & 22 \\
\hline Beijing & 12 & 22 & 2 & 11 & 18 & 14 \\
\hline
\end{tabular}


TABLE 10: Regions with second-level and fourth-level competitiveness.

\begin{tabular}{|c|c|c|c|c|c|c|}
\hline Area & $\begin{array}{c}\text { Evaluation index } \\
\text { value ranking } \\
{[0-0.3]}\end{array}$ & $\begin{array}{l}\text { Factor base } \\
\text { ranking }\end{array}$ & $\begin{array}{l}\text { Industrial } \\
\text { demand condition } \\
\text { ranking }\end{array}$ & $\begin{array}{l}\text { Enterprise competitiveness } \\
\text { and growth power ranking }\end{array}$ & $\begin{array}{c}\text { Relevant and } \\
\text { supporting } \\
\text { industries }\end{array}$ & $\begin{array}{c}\text { Natural } \\
\text { environment factor } \\
\text { ranking }\end{array}$ \\
\hline Sichuan & 13 & 10 & 17 & 17 & 5 & 31 \\
\hline Tianjin & 14 & 21 & 4 & 13 & 24 & 15 \\
\hline Ningxia & 15 & 14 & 8 & 21 & 29 & 7 \\
\hline Guangxi & 16 & 25 & 25 & 16 & 8 & 18 \\
\hline Jilin & 17 & 24 & 29 & 15 & 13 & 5 \\
\hline Hunan & 18 & 23 & 28 & 23 & 6 & 21 \\
\hline Xizang & 19 & 11 & 10 & 31 & 30 & 1 \\
\hline Hubei & 20 & 17 & 20 & 20 & 11 & 25 \\
\hline Zhejiang & 21 & 20 & 5 & 23 & 16 & 28 \\
\hline Fujian & 22 & 28 & 11 & 27 & 12 & 2 \\
\hline Anhui & 23 & 19 & 13 & 18 & 15 & 26 \\
\hline Shaanxi & 24 & 12 & 19 & 17 & 25 & 11 \\
\hline Yunnan & 25 & 16 & 27 & 20 & 22 & 3 \\
\hline Jiangxi & 26 & 27 & 22 & 25 & 8 & 9 \\
\hline Qinghai & 27 & 19 & 24 & 27 & 31 & 6 \\
\hline Gansu & 28 & 15 & 26 & 25 & 28 & 14 \\
\hline Chongqing & 29 & 29 & 15 & 28 & 19 & 29 \\
\hline Hainan & 30 & 31 & 30 & 30 & 26 & 10 \\
\hline Guizhou & 31 & 30 & 31 & 29 & 27 & 30 \\
\hline
\end{tabular}

TABLE 11: Comparison of competitiveness evaluation results of China's dairy industry based on time dimension.

\begin{tabular}{lcccccccccc}
\hline Comprehensive level & 2007 & 2008 & 2009 & 2010 & 2011 & 2012 & 2013 & 2014 & 2015 & 2016 \\
\hline GAG-PP & 0.1216 & 0.2833 & 0.4066 & 0.4794 & 0.6343 & 0.6422 & 0.7326 & 0.7442 & 0.7514 & 0.8267 \\
AHP & 0.1725 & 0.3954 & 0.4870 & 0.5759 & 0.7066 & 0.5001 & 0.5053 & 0.5635 & 0.5846 & 0.6297 \\
Entropy weight & 0.2741 & 0.2484 & 0.3521 & 0.4171 & 0.5001 & 0.4980 & 0.6054 & 0.5951 & 0.6701 & 0.6218 \\
\hline
\end{tabular}

As shown in Figures 6 and 7, the results of AHP and entropy weight of time dimension and space dimension data of China's dairy industry competitiveness are quite different. The main reason is that AHP is based on the main experience of experts, while entropy weight is only based on the weight of data. Once the data distribution is relatively uniform, entropy weight loses its significance.

According to the comparison of the evaluation results of the competitiveness of China's dairy industry based on the time dimension in Table 11, it can be seen that there are certain differences in the calculation results of the three, but the overall competitiveness development trend from 2007 to 2016 is basically the same, showing a great increase in competitiveness. Combined with the relevant research in this paper and the actual situation of China's dairy industry competitiveness, GAG-PP shows that the competitiveness of China's dairy industry in the time dimension presents an upward trend year by year. The AHP shows that the competitiveness of China's dairy industry presents an inverted " $U$ " shape in the time dimension, while the entropy weight shows that the competitiveness of China's dairy industry fluctuated greatly from 2013 to 2016 . Combined with the research results of $[38,41,42]$ and consulting relevant experts, it is considered that only GAG$\mathrm{PP}$ results can more accurately reflect the actual evaluation of dairy industry competitiveness, which shows that GAG-PP can improve the accuracy and scientificity of evaluation.
The comparison of the calculated time dimension competitiveness evaluation value competitiveness evaluation value results is shown in Table 12. Although the final classification results of the three models are relatively close, there are also small fluctuations. For example, in the regions in the first level of dairy industry competitiveness, the ranking results of GAG-PP and entropy weight are Inner Mongolia $>$ Shandong $>$ Heilongjiang $>$ Hebei, the ranking results of AHP are Inner Mongolia $>$ Heilongjiang $>$ Shandong $>$ Hebei, from the actual situation, and the ranking results of AHP are not very consistent with the actual situation, which shows that the results of AHP are subjective. The ranking results of GAG-PP are Henan $>$ Guangdong $>$ Liaoning $>$ Xinjiang $>$ Shaanxi $>$ Shanghai $>$ Jiangsu $>$ Beijing, the ranking results of AHP are Xinjiang $>$ Henan $>$ Tibet $>$ Liaoning $>$ Shaanxi $>$ Guangdong $>$ Jiangsu $>$ Shanghai, and the ranking results of entropy weight are HeNan $>$ Guangdong $>$ Xinjiang $>$ Shaanxi $>$ Liaoning $>$ Shanghai $>$ Jiangsu $>$ Tibet. Although, in the second level of regional ranking, both entropy weight and AHP have Tibet region, from the actual situation of the competitiveness of Tibetan dairy products, it is not particularly prominent, but the results caused by the model are not very consistent with the reality, so the ranking results of GAG-PP can more truly reflect the actual situation of the competitiveness of China's dairy industry. 


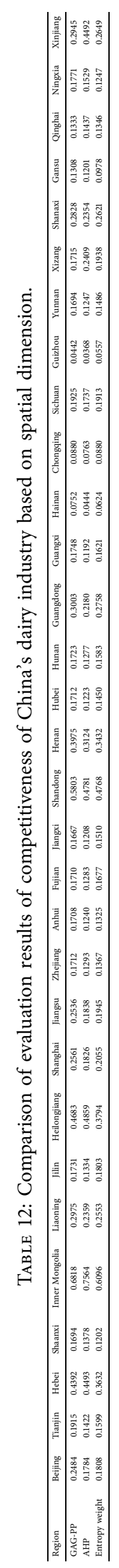




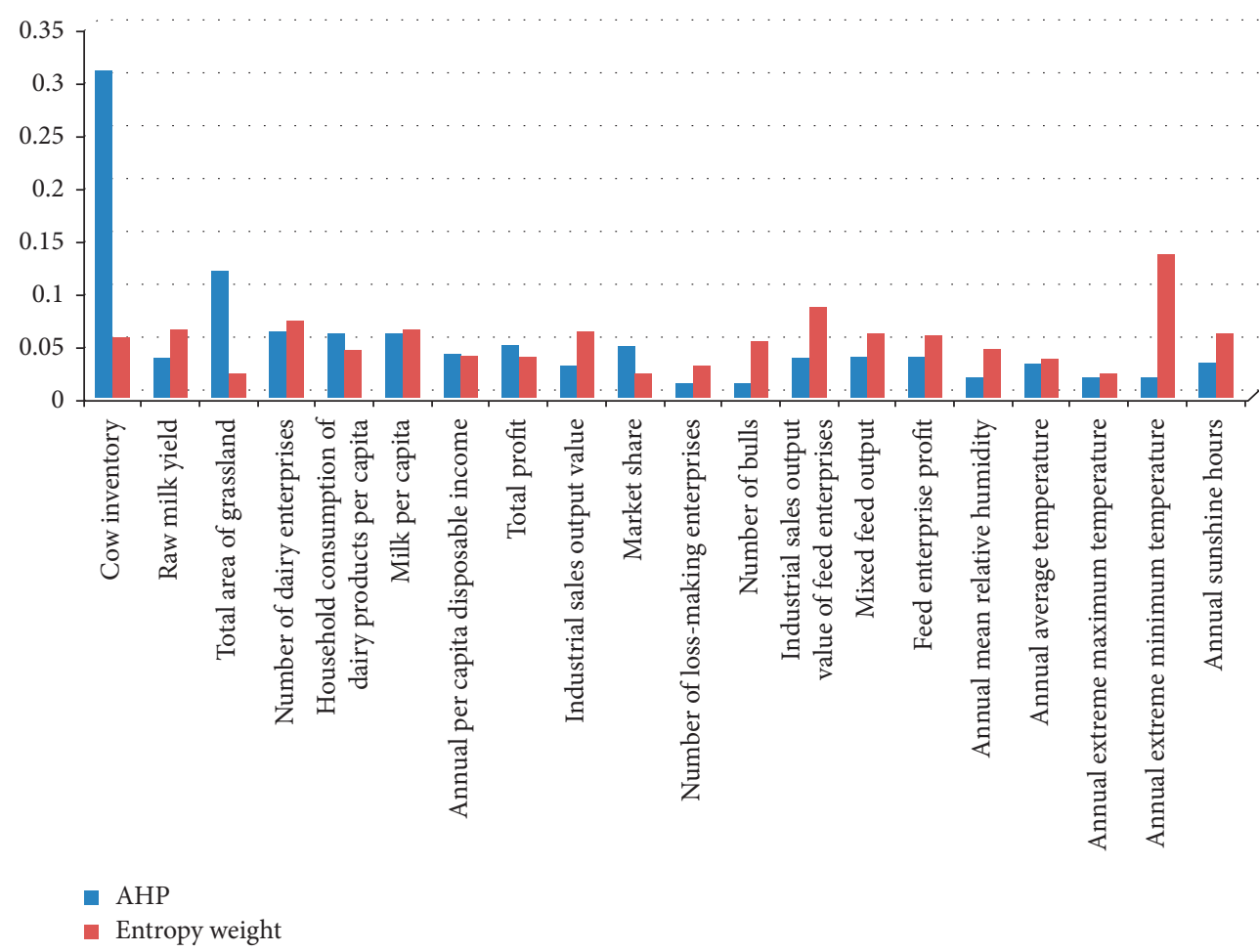

FIGURE 6: AHP and entropy weight of time dimension data of China's dairy industry competitiveness.

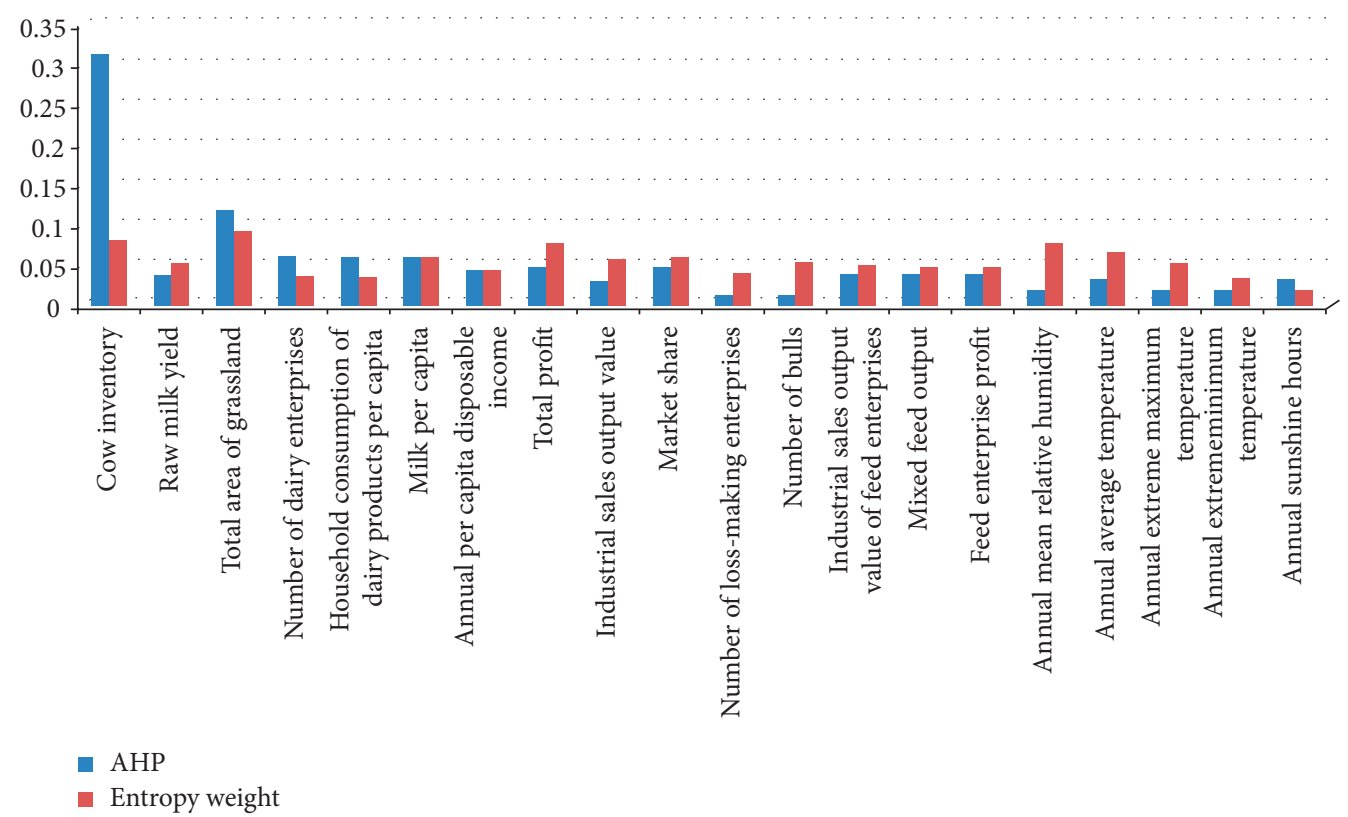

FIGURE 7: AHP and entropy weight of spatial dimension data of China's dairy industry competitiveness.

\section{Conclusions and Recommendations}

This paper selected the factors of production factor base, industry demand conditions, enterprise competitiveness and growth force, related and supporting industries, and natural environmental elements as five dimensions and evaluated the competitiveness of China's dairy industry by means of accelerating genetic projection pursuit model from two perspectives of time and space. The results show that competitiveness of China's dairy industry in time presents the overall good development momentum, but from the point of view on the space it shows a larger difference. At the same time, the optimal projection direction of each evaluation index based on time and space dimensions indicates that the number of loss-making enterprises, the number of hours of sunshine in a year, and raw milk output are 
relatively consistent in their importance to the competitiveness of China's dairy industry, among which the most important is to increase raw milk output. Therefore, the dairy breeding technology innovation can be enhanced to improve the dairy breed structure by improving dairy breed. Meanwhile, forage and feed varieties can be optimized and standardized to improve the yield of milk. In addition, learning the advanced technology and advanced management experience from other countries can promote the overall strength of the dairy industry.

\section{Data Availability}

The data used to support the findings of this study are available from the corresponding author upon request.

\section{Conflicts of Interest}

The authors declare no conflicts of interest.

\section{Acknowledgments}

This work was supported by the National Natural Science Foundation of China (Project no. 71874184), Xinjiang Tianshan Army Reclamation Co., Ltd (Project no. 2019ZH04), Key Scientific and Technological Research Project in Key Fields of Xinjiang Production and Construction Corps (Project no. 2018AB041), and Modern Agricultural Science and Technology Research and Achievement Transformation Project of the Eighth Division (Project no. 2018NY05).

\section{References}

[1] Minstry of Agriculture and Rural Affairs of the People's Republic of China, Nine Ministries and Commissions Including the Ministry of Agriculture and Rural Areas Jointly Issued Several Opinions on Further Promoting the Revitalization of Dairy Industry, Minstry of Agriculture and Rural Affairs of the People's Republic of China, Beijing, China, 2018, http://www. moa.gov.cn/xw/zwdt/201812/t20181226_6165640.htm. 2020.6. 5.

[2] Prospective Industry Research Institute, China Dairy Industry Market Demand Forecast and Investment Strategic Planning Analysis Report, Prospective Industry Research Institute, Beijing, China, 2019, https://www.qianzhan.com/analyst/detail/ 220/200514-be029970.html. 2020.6.5.

[3] M. Porter, National Competitive Advantage, Huaxia Press, Beijing, China, 2002.

[4] M. Peter, "Ricardian-Heckscher-Ohlin comparative advantage: theory and evidence," Journal of International Economics, vol. 82, no. 2, pp. 137-151, 2010.

[5] B. R. Copeland and A. Kotwal, "Product quality and the theory of comparative advantage," European Economic Review, vol. 40, no. 9, pp. 1745-1760, 1996.

[6] K. Paul, Pop Internationalism, MIT Press, Boston, MA, USA, 1996.

[7] X. Luo, "Coastal tourism commodity industry cluster based on diamond model and ecological Niche," Journal of Coastal Research, vol. 94, no. 1, p. 828, 2019.

[8] K. Fang, Y. Zhou, S. Wang, R. Ye, and S. Guo, "Assessing national renewable energy competitiveness of the G20: a revised Porter's diamond model," Renewable and Sustainable Energy Reviews, vol. 93, pp. 719-731, 2018.

[9] T. W. Chung, "A study on logistics cluster competitiveness among Asia main countries using the Porter's diamond model," The Asian Journal of Shipping and Logistics, vol. 32, no. 4, pp. 257-264, 2016.

[10] S. Fainshmidt, A. Smith, and W. Q. Judge, "National competitiveness and Porter's diamond model: the role of MNE penetration and governance quality," Global Strategy Journal, vol. 6, no. 2, pp. 81-104, 2016.

[11] G. Li and S. Lu, “Transformation advantages of China's hightech manufacturing industry-empirical analysis based on comprehensive advantage strategy theory," Journal of Shanxi University of Finance and Economics, vol. 41, no. 11, pp. 55-68, 2019.

[12] C. Tan and L. Liu, “The differential effect of knowledge capital on the intensive and extensive complexity of national advantageous industrial portfolio," International Economics and Trade Research, vol. 35, no. 7, pp. 40-53, 2019.

[13] Y. He, Q. Han, and Y. Zeng, "A research on the impact of indigenous innovation on international competitiveness of China's manufacturing industry," Science Research Management, vol. 40, no. 7, pp. 33-46, 2019.

[14] T. Zhang, "Sources of national competitive advantages-knowledge production, knowledge capitalization and manufacturing base," Exploration and Free Views, no. 7, pp. 136-146, 2019.

[15] F. Zhou, "Study on evaluation index system of regional crossborder electronic commerce industry," Journal of Chongqing University of Technology (Natural Science), vol. 33, no. 1, pp. 201-209, 2019.

[16] M. K. Singh, H. Kumar, M. P. Gupta, and J. Madaan, “Analyzing the determinants affecting the industrial competitiveness of electronics manufacturing in India by using TISM and AHP," Global Journal of Flexible Systems Management, vol. 19, no. 3, pp. 191-207, 2018.

[17] J. Xu and Y. Liu, "Evaluation of industrial competitiveness based on BMK and AHP analysis," Soft Science, vol. 25, no. 3, pp. 70-73, 2011.

[18] B. Yan, R. Ren, and M. Wang, "AHP and fuzzy evaluation of competitiveness of China's auto industrial clusters," Journal of Southwest Jiaotong University, vol. 8, no. 4, pp. 12-18, 2007.

[19] S. Liu, X. Ye, and W. Chen, "Analysis of competitiveness of characteristic industrial cluster based on AHP-a case study of ceramic industrial cluster in Jiangxi, Guangdong and Fujian," China Soft Science, no. 8, pp. 141-146, 2005.

[20] H. Li, S. Wang, and Q. Xie, "Research on oil industrial competitiveness in Shandong based on principal component analysis," Modern Management, vol. 1, pp. 125-130, 2011.

[21] L. Cui and L. Zhang, "the evaluation of the competitiveness of high-tech industry in coastal provinces in China," Emergence and Transfer of Wealth, vol. 4, no. 3, pp. 31-40, 2014.

[22] D. Chen, D. Yang, H. Li, and L. Chen, "Dynamic competitiveness of segmentation of construction industry based on principal component analysis," Journal of Engineering Management, vol. 31, no. 2, pp. 38-42, 2017.

[23] S. Yan, "Assessment of Beijing's new energy industry based on AHP-FCE comprehensive evaluation," Science and Technology Management Research, vol. 37, no. 7, pp. 93-97, 2017.

[24] W. Yu, "Research on the comprehensive evaluation model of regional sports industry competitiveness based on PCA and NNS," Journal of Sichuan Normal University, vol. 38, no. 4, pp. 624-628, 2015.

[25] C. Yang, X. Li, and S. Zhang, "Comparative research on competitiveness of Suzhou service outsourcing industry based 
on multi-step fuzzy comprehensive evaluation," Science and Technology Management Research, vol. 33, no. 17, pp. 65-71, 2013.

[26] J. Du and Y. Liu, "Regional dierences of development level of creative cultural industry in Jiangsu province based on grey relational clustering model," Generalized Virtual Economy, vol. 10, no. 2, pp. 67-74, 2019.

[27] G. Wang, W. Chen, and Q. Cao, "An empirical study on influencing factors and impact mechanism of forestry industry competitiveness based on the structural equation model," Journal of Ocean University of China, no. 2, pp. 72-78, 2019.

[28] Y. Hu and T. Wu, "Research on the evaluation of distribution industry competitiveness for region based on SEM," Journal of UESTC (Social Sciences Edition), pp. 1-7, 2019.

[29] Q. Guo and T. Liu, "Synergistic effect of technological innovation, industrial structure and financial development," Journal of Shandong University of Science and Technology, vol. 19, no. 5, pp. 61-67, 2017.

[30] M. Zu and W. Zhou, "Grey correlation analysis between the technological innovation ability and automobile industry competitiveness," Journal of Anhui University of Technology, vol. 33, no. 6, pp. 12-14, 2016.

[31] X. Ruan and R. Shi, "Study on the evaluation of competitiveness of new energy automobile industry based on grey correlation model," Mathematics in Practice and Theory, vol. 46, no. 21, pp. 72-79, 2016.

[32] H. Zhang and Y. Zhang, "Evaluation of tourism industry competitiveness in western Hunan based on structural equation model," Journal of Jishou University, vol. 35, no. S2, pp. 32-35, 2014.

[33] H. Zhou, "An empirical analysis of the influence of industrial agglomeration on the competitiveness of Zhejiang manufacturing industry," Productivity Study, no. 9, pp. 132134, 2013.

[34] L. Chen and Y. Liang, "Research on the relevance between the degree of mineral industrial agglomeration and industrial competitiveness in China's western region," China Population, Resources and Environment, vol. 21, no. 5, pp. 31-37, 2011.

[35] T. Hui and X. Yang, "Research on the level of specialization competitiveness of cultural industry based on location entropy measurement," Gansu Finance, no. 8, pp. 63-67, 2019.

[36] C. Liu, L. Han, and Y. Zhang, "International comparison and development suggestions of China's dairy industry competitiveness," Chinese Rural Economy, no. 7, pp. 130-144, 2018.

[37] X. Cheng, "Study on the influence of Chinese dairy industry agglomeration on industrial competitiveness," Economic Forum, no. 4, pp. 95-98, 2018.

[38] Z. Ma and Y. Yang, "Competitiveness evaluation and strategy selection of dairy industry in China," Reformation and Strategy, vol. 33, no. 8, pp. 158-162, 2017.

[39] Y. Bian, "Analysis on international competitiveness of Chinese dairy industry," Journal of Hebei University of Economics and Business (Comprehensive Edition), vol. 16, no. 4, pp. 9195, 2016.

[40] Y. Zhang, A. Ren, and J. Zhao, "Analysis on milk powder international competitiveness based on diamond model," Chinese Journal of Agricultural Resources and Regional Planning, vol. 37, no. 2, pp. 84-90, 2016.

[41] Y. Han and X. Cheng, "An empirical study on regional competitiveness of China's dairy industry-a dynamic analysis based on multidimensional panel data," Forward Position, no. 8, pp. 63-66, 2015.
[42] S. Seyiti and F. Deng, "Evaluation of regional dairy industry competitiveness based on AHP," Statistics and Decision, no. 14, pp. 67-69, 2013.

[43] J. H. Friedman and W. Stuetzle, "Projection pursuit regression," Journal of the American Statistical Association, vol. 76, no. 376, pp. 817-823, 1981.

[44] Y. Gong, Y. Zhang, F. Ding, J. Hao, H. Wang, and D. Zhang, "Projection pursuit model for assessment of groundwater quality based on firefly algorithm," Journal of China University of Mining \& Technology, vol. 44, no. 3, pp. 566-572, 2015.

[45] M. Porter, "Competitive Strategy Techniques for Analyzing Industries and Competitors," The Free Press, New York, NY, USA, 1980.

[46] D.-S. Cho and H. Chang Moon, “A nation's international competitiveness in different stages of economic development," Advances in Competitiveness Research, vol. 6, pp. 5-19, 1998.

[47] J. H. M. Wijnands, H. J. Bremmers, B. M. J. Meulen, and K. J. van der Poppe, Competitiveness and Innovativeness of the EU Dairy Industry, Wageningen Academic Publishers, Wageningen, Netherlands, 2010.

[48] M. Nica, "Analysis of competitiveness on the market of milk and dairy products in Romania," in Proceedings of the Agrarian Economy and Rural Development-Realities and Perspectives for Romania, Bucharest, Romania, November 2017.

[49] O. Ramphul, "Global competitiveness in dairy sector," Social Science Electronic Publishing, vol. 59, no. 5, pp. 257-264, 2016.

[50] Q. Xu, Analysis on the Regional Competitiveness of China's Dairy Industry, Southwestern University of Finance and Economics, Chengdu,China, 2014.

[51] J. H. Friedman and J. W. Tukey, "A projection pursuit algorithm for exploratory data analysis," IEEE Transactions on Computers, vol. C-23, no. 9, pp. 881-890, 1974.

[52] Q. Cheng, "Structure entropy weight method to confirm the weight of evaluating index," System Engineering Theory and Practice, vol. 30, no. 7, pp. 1225-1228, 2010. 